\title{
Knowledge of Antibiotic Use in College Students: A Quality Improvement Project
}

\author{
Katie Moes DNP, APRN \\ Catherine Carrico DNP, APRN \\ Alexander Hall, MS \\ Creighton University
}

\begin{abstract}
Aim: To evaluate college students' knowledge, attitudes, and beliefs about antibiotic use for simple viral infections, as well as determine if knowledge could be improved through an educational intervention and examine impacts on overall patient satisfaction.

Background: Antibiotic resistance is a growing problem. College-aged students are at an increased risk for simple respiratory infections due to their close living conditions and poor knowledge of appropriate antibiotic use (Smith, Rigassio-Radler, Denmark, Haley, \& Touger-Decker, 2012; Turner \& Keller, 2015). Methods: Students $(N=44)$ age 19-25 seen at the college health center of a small, private Nebraska university presenting with symptoms of an upper respiratory infection (URI) were given a survey prior to seeing the healthcare provider. During the visit, providers reviewed an educational handout discussing appropriate antibiotic use for URIs and then gave the student a post-survey to complete.

Results: Students' Basic Knowledge of antibiotics improved, $p=.1$, Cohen's $d=0.41$ as a result of the educational intervention, while changes in knowledge about Efficacy and Provider trust was mixed. Knowledge of correct use/misuse was high at pre, $M=1.95$ and post $M=1.93$.

Conclusions: College-aged students benefit from additional education about antibiotics. Based on this project's findings, educational handouts have the potential to improve knowledge regarding antibiotics.
\end{abstract}

Submitted 15 March 2018: accepted 23 July 2018

Keywords: college students, antibiotics, upper respiratory infection, patient education

Antibiotic resistance is a worldwide problem, contributing to rising healthcare costs, and the mutation of bacteria leading to serious, life-threatening infections. In the United States (US), two million people acquire resistant bacterial infections annually and 23,000 people die each year as a result of these antibiotic-resistant bacterial infections (Centers for Disease Control and Prevention, 2013).

Resistant bacterial infections have been attributed to the overprescribing and misuse of antibiotics, specifically for upper respiratory infections (URIs; Crocker et al., 2013). Only 60\% of prescribed antibiotics are clinically indicated and only 20\% are the recommended first-line choice. (Barlam, Soria-Saucedo, Cabral, \& Kazis, 2016; Fairlie, Shapiro, Hersh, \& Hicks, 2012). Patients overestimate their knowledge of antibiotics and have misconceptions about appropriate antibiotic use including antibiotics treat viral infections (such as the common cold), shorten illness time, and that there is no risk associated with the overuse of antibiotics (Broniatowski, Klein, \& Reyna, 2015). Providers prescribe antibiotics for URIs out of fear of conflict, patient loss, and the assumption that the patient expects an 
antibiotic. (Dempsey, Businger, Whaley, Gagne, \& Linder, 2014; Fletcher-Lartey, Yee, Gaarslev, \& Kahn, 2016). The relationship between antibiotics and visit satisfaction varies in the literature, with some studies finding patients who received antibiotics were more satisfied than those who did not (Ashworth, White, Jongsma, Schofield, \& Armstrong, 2016; Haltiwanger, Hayden, Weber, Evans, \& Possner, 2001). In contrast, a multi-country study found patients were satisfied with the visits regardless of whether or not they were prescribed antibiotics (Coenen et al., 2013.)

Studies have consistently shown that younger patients are more likely to seek out healthcare, have less knowledge about antibiotics, and are more likely to misuse antibiotics (Gaarslev, Yee, Chan, Fletcher-Larety, \& Kahn, 2016; Smith, Kern, Chandra, Tan, \& Evans, 2013). The reason for this discrepancy is not well understood, and data regarding this age group is limited.

College students are thought to be at an increased risk for respiratory infections due to stress, lack of sleep, and shared work, study, and living environments (Smith et al., 2012; Turner \& Keller, 2015). Upper respiratory infections lead to over 4,000 missed days of class and over 17,000 days of reduced productivity among college students (Nichol, D’Heilly, \& Ehlinger, 2005). College students' increased risk for respiratory infections accompanied by busy work, school, and social schedules fuel the desire for a quick remedy, often in the form of an antibiotic (Haltiwanger et al., 2001; Nichol et al., 2005).

Furthermore, many college students have their first autonomous encounter with the healthcare system at a college student health center, making their visits with student health a significant influence on establishing independent health behaviors (Nicoteri \& Arnold, 2005; Unwin, Goodie, Reamy, \& Quinlan, 2013). Students may seek out healthcare after just a few hours of symptoms and are not aware of over-the-counter or comfort remedies they can try on their own (Nicoteri \& Arnold, 2005). The literature is limited regarding antibiotic use in the college student population despite this age groups' increased risk for infection, lower antibiotic knowledge, and increased likelihood of antibiotic misuse. Research on this topic is particularly limited in the US, with one study finding college students rated higher satisfaction with the overall visit when prescribed an antibiotic (Haltiwanger et al., 2001).

Providers are the primary sources of patient education on antibiotics, but despite this finding, one-third of patients felt they got too little or no information from the provider (Cals et al., 2007).Patient knowledge has been shown to be improved through the use of educational handouts resulting in increased patient confidence and comfort-level in self-care, a fitting goal for college-aged students experiencing their first independent encounter in healthcare (Macfarlane et al., 2002; Moerenhout et al., 2013; Wutzke et al., 2006).

The purpose of this quality improvement (QI) project was to evaluate college students' knowledge, attitudes, and beliefs regarding antibiotic use for uncomplicated viral infections. The aims of this QI project were a) to determine if antibiotic knowledge improves with an educational intervention and b) determine if this impacts the patient satisfaction of the visit.

\section{METHODS}

The project was deemed QI through the university's Institutional Review Board (IRB). The Health Belief Model was used to guide this project. The Health Belief Model (HBM) proposes that an individual's belief about the threat of a health problem along with perceived benefits of the action and barriers to the action, as well as the individual's selfefficacy, identify their decision to act in regards to a health-related behavior (Katz, Elmore, Wild, \& Lucan, 2014). The HBM suggests that in order for a student to seek health care for their URI, they must feel that the illness is severe, 
they are at risk for developing the illness, the behavior (antibiotic use) is successful at preventing or reducing illness, and there are no risks or barriers to performing the behavior.

\section{Procedure}

This QI project took place at the student health center of a private Nebraska university from September 1, 2017 December 11, 2017. The university consists of approximately 8,000 undergraduate and graduate students. Clinic nurses identified eligible participants as they checked into the health center. This project utilized a pre-survey, provider-led review of an educational handout and post-survey.

Initially, the patient was to return the post-visit survey in a stamped, pre-addressed envelope within one week of the visit. However, due to a poor response rate after four weeks, the students were asked to complete the post-visit survey before leaving the clinic. The next ten weeks yielded an improved response.

An educational handout was created in collaboration with the student health center (Figure 1). The two providers had been using the educational handout prior to this project, however, additions were made after themes were identified from the Broniatowski et al. study (2015). The following major themes were identified from the Broniatowski et al. survey and selected for inclusion on side B of the educational handout: What antibiotics treat, potential side effects, risks of antibiotic misuse, and how to appropriately take antibiotics (2015). Side A consisted of a list of over-the-counter medications for providers to check or highlight for each final patient diagnosis.

\begin{tabular}{|c|c|}
\hline \multicolumn{2}{|c|}{ Cold Care Instructions } \\
\hline \multicolumn{2}{|c|}{ Get plenty of rest and stay hydrated } \\
\hline MEDICATION & USE \\
\hline $\begin{array}{l}\text { Ibuprofen (Advil, Motrin) } \\
\text { tablets every 6-8 hours } \\
\text { OR } \\
\text { Naproxen (Aleve) } 220 \mathrm{mg} \\
1 \text { tablet every } 12 \text { hours } \\
\end{array}$ & $\begin{array}{l}\text { For fever, pain and inflammation } \\
\text { Take with food }\end{array}$ \\
\hline $\begin{array}{c}\text { Acetaminophen (Tylenol) } \\
2 \text { tablets every } 6 \text { hours } \\
\text { No more than } 8 \text { tablets ( } 4000 \mathrm{mg} \text { ) in } 24 \text { hours }\end{array}$ & $\begin{array}{l}\text { For fever and pain } \\
\text { Avoid alcohol }\end{array}$ \\
\hline \multicolumn{2}{|c|}{ Aspirin is NOT recommended while ill } \\
\hline $\begin{array}{l}\text { Pseudoephedrine (Sudafed } 12 \text { hour) } \\
\text { Better than phenylephrine } \\
\text { Available only at pharmacy counter }\end{array}$ & $\begin{array}{l}\text { Decongestant used to treat congestion of the } \\
\text { sinuses, ears, and chest }\end{array}$ \\
\hline $\begin{array}{l}\text { Loratadine (Claritin) } 1 \text { tablet daily } \\
\text { Cetirizine (Zyrtec) } 1 \text { tablet daily } \\
\text { Fexofenadine (Allegra) } 1 \text { tablet daily } \\
\text { Diphenhydramine (Benadryl) } 25 \mathrm{mg} \\
1-2 \text { tablets every } 6 \text { hours }\end{array}$ & $\begin{array}{l}\text { Antihistamines for allergy symptoms, runny } \\
\text { nose, and congestion } \\
\text { Diphenhydramine may cause drowsiness }\end{array}$ \\
\hline $\begin{array}{l}\text { Guaifenesin (Mucinex) } \\
\text { Guaifenesin/Pseudoephedrine (Mucinex D) } \\
\text { Guaifenesin/Dextromethorphan (Mucinex DM) }\end{array}$ & $\begin{array}{c}\text { Guaifenesin: } \text { mucus thinner } \\
D=\text { decongestant(pseudoephedrine) } \\
D M=\text { cough suppressant (dextromethorphan) }\end{array}$ \\
\hline $\begin{array}{l}\text { Dextromethorphan (Delsym } 12 \text { hour) } \\
\text { Guaifenesin/Dextromethorphan (Robitussin DM) }\end{array}$ & Cough Control \\
\hline Nasal saline washes/sprays & Cleans/moistens nasal passages \\
\hline $\begin{array}{l}\text { Flonase (fluticasone) } \\
\text { Nasacort (triamcinolone) } \\
\text { Rhinocort (budesonide) }\end{array}$ & Nasal steroid for sneezing, itching, \& runny nose \\
\hline \multicolumn{2}{|c|}{$\begin{array}{l}\text {-Read all labels carefully to ensure that you take medication properly } \\
\text {-If pregnant, consult your provider prior to taking any medication } \\
\text {-Seek care for severe symptoms (short of breath, excessive vomiting, persistent high fever >102) }\end{array}$} \\
\hline
\end{tabular}

\begin{tabular}{|l|l|}
\hline \multicolumn{1}{|c|}{ Virus } & \multicolumn{1}{|c|}{ Bacteria } \\
\hline Cold & Sinus infection \\
\hline Mononucleosis & Strep Throat \\
\hline Influenza & Pneumonia \\
\hline Bronchitis & \\
\hline
\end{tabular}

Antibiotics do NOT:

- Treat viruses: colds or flu, most coughs/bronchitis, sore throats (not caused by strep), and runny noses

- Reduce symptoms or make you better when you have a virus

- Keep others from catching your viral illness

- Keep a viral illness from getting worse

Antibiotics DO:

- Only treat bacterial infections: strep throat, some pneumonia, bacterial sinus infection

Antibiotics CouLD cause:

- Side effects (stomach upset, diarrhea)

- Allergic reaction

- Vaginal yeast infection

- Interaction with prescription and non-prescription medications

- Antibiotic resistance

IF you have been prescribed an antibiotic:

- Complete the full course as prescribed, even if you begin to feel better

- Do not share or save antibiotics

- Do not take antibiotics leftover from a previous illness

Figure 1. Side A and Side B of the educational handout. 


\section{Survey}

A 17-item survey evaluating patient knowledge of URIs and primarily consisting of five-point Likert-scale items was adapted with permission from Broniatowski and colleagues (2015). Broniatowski et al. created this survey for use in an emergency department (ED) setting and items were created through a review of relevant literature and physician interviews (2015). Exploratory factor analysis (EFA) was conducted and identified three potential dimensions, however no attempt was made to define the factors or suggest item modifications (Broniatowski et al., 2015). For this project, three items were reclassified as dichotomous and discretized: (1) Antibiotics work against bacteria, (2) Antibiotics work against viruses, and (3) Antibiotics work against all germs. Two additional items were added in order to assess students' knowledge of antibiotic misuse: (1) I can stop taking my antibiotics early if I begin to feel better and (2) I can share my antibiotic with my friend or family member who is also sick. These statements were added based on findings in the literature specific to the college-age patient. Pre and post surveys were anonymous and identical. All data were anonymous, and pretest post-test matching was done via a unique deidentified ID variable. The pre and post-visit surveys were estimated to take no more than 10 minutes each to complete.

The provider checked a final diagnosis on the post-visit survey and gave the patient the post-survey upon completion of the visit. Students were provided with a Bill of Rights prior to filling out any data and permission was assumed upon completion of the survey. Students returned completed surveys to a member of the medical staff. The completed surveys were stored in a locked cabinet and collected upon conclusion of the project. An example of the survey is listed in Appendix-I.

\section{Data Analyses}

Questions were grouped as follows: Questions 1-3 addressed Basic Antibiotic Knowledge, questions 4 - 11 focused on Antibiotic Efficacy and Risk versus Benefits of Taking Antibiotics, questions 12 - 17 addressed the students' trust in the provider's decision (Provider Trust), and questions 18 - 19 addressed Appropriate Management of Prescriptions. A sum score was created for antibiotic knowledge (with a max score of three), as well as for appropriate management of prescriptions (with a max score of two). Paired sample $t$-tests were used to analyze pre and post responses for both dimensions.

Antibiotic Efficacy/Risk versus benefit (Q 4-11) and Provider Trust (Q12-17) were considered opinion-based questions with no absolute right or wrong but were considered to have a "more correct" opinion. For example, the vast majority of upper respiratory infections, whether viral or bacterial, do resolve without antibiotics, thus while the question "My symptoms will only go away with antibiotics" is subjective, responses of agree and strongly agree are more indicative of adequate knowledge than neither agree nor disagree, disagree, and strongly disagree. Pre-and-post improvement was evaluated in terms of if the opinions moved in a more "correct" or less "correct" direction. Items that had no change for pre/post were recorded as 0,1 was recorded if the post-answer moved in the more correct direction, and -1 if the answer moved in the more incorrect direction. Due to inherent limitations in measurement precision, movements from strongly agree to agree are treated the same way as a movement from strongly agree to neither agree nor disagree. Paired sample $t$-tests were conducted on pre and post responses for both dimensions, but due to measurement limitations should be interpreted conservatively. All analyses were conducted using SPSS version 25. 


\section{Results}

Table 1

Demographics

\begin{tabular}{|c|c|c|}
\hline$N=44$ & Frequency $(\%)$ & Median (q1, q3) \\
\hline Age & & $20(19,21)$ \\
\hline Year & & $3(2,4)$ \\
\hline \multicolumn{3}{|l|}{ College } \\
\hline College of Arts and & $19(43 \%)$ & \\
\hline Sciences & & \\
\hline College of Nursing & $6(14 \%)$ & \\
\hline College of Professional & $1(2 \%)$ & \\
\hline Studies & & \\
\hline College of Business & $10(23 \%)$ & \\
\hline School of Law & 0 & \\
\hline Post Graduate Health & $8(18 \%)$ & \\
\hline Professionals & & \\
\hline \multicolumn{3}{|l|}{ Final Diagnosis $(\mathrm{n}=39)$} \\
\hline Common cold/ Viral URI & $20(51 \%)$ & \\
\hline Bronchitis & $3(8 \%)$ & \\
\hline Sinusitis (Viral) & $1(3 \%)$ & \\
\hline Sinusitis (Bacterial) & $5(13 \%)$ & \\
\hline Pharyngitis (Viral) & $7(18 \%)$ & \\
\hline Streptococcal Pharyngitis & $2(5 \%)$ & \\
\hline Mono & $1(3 \%)$ & \\
\hline Influenza & 0 & \\
\hline Other & 0 & \\
\hline Antibiotics given & $11(25 \%)$ & \\
\hline Understand why or why not given & $35(80 \%)$ & \\
\hline Satisfied with visit & $43(98 \%)$ & \\
\hline
\end{tabular}

Student Antibiotic Knowledge at T1 had a mean score of $2.2(S E=.15)$, while at T2 the mean was 2.5 (SE = $.12)$, this difference, $.3,95 \%$ CI $[.07, .53]$, was significant $t(41)=2.68, p=.01$, Cohen's $d=.41$. The knowledge of Appropriate Management of Prescriptions portion had a T1 mean of 1.95 (SE =.03), and at T2 the mean was 1.93 $(S E=.04)$, this difference, $-.02,95 \%$ CI [-.07, .02], was not significant $t(41)=1, p=.01$, Cohen's $d=.15$, and likely represents a ceiling effect consistent with high baseline knowledge.

Risk Versus Benefit knowledge had a mean change of .74 items, with Bonferroni adjusted 95\% CI [-.11, 1.58], while Provider Trust had a mean change of .46 items, with Bonferroni adjusted 95\% CI [-.14, 1.07]. Change in knowledge for these dimensions can be seen in Figure 2 and reflect uncertain intervention efficacy. 

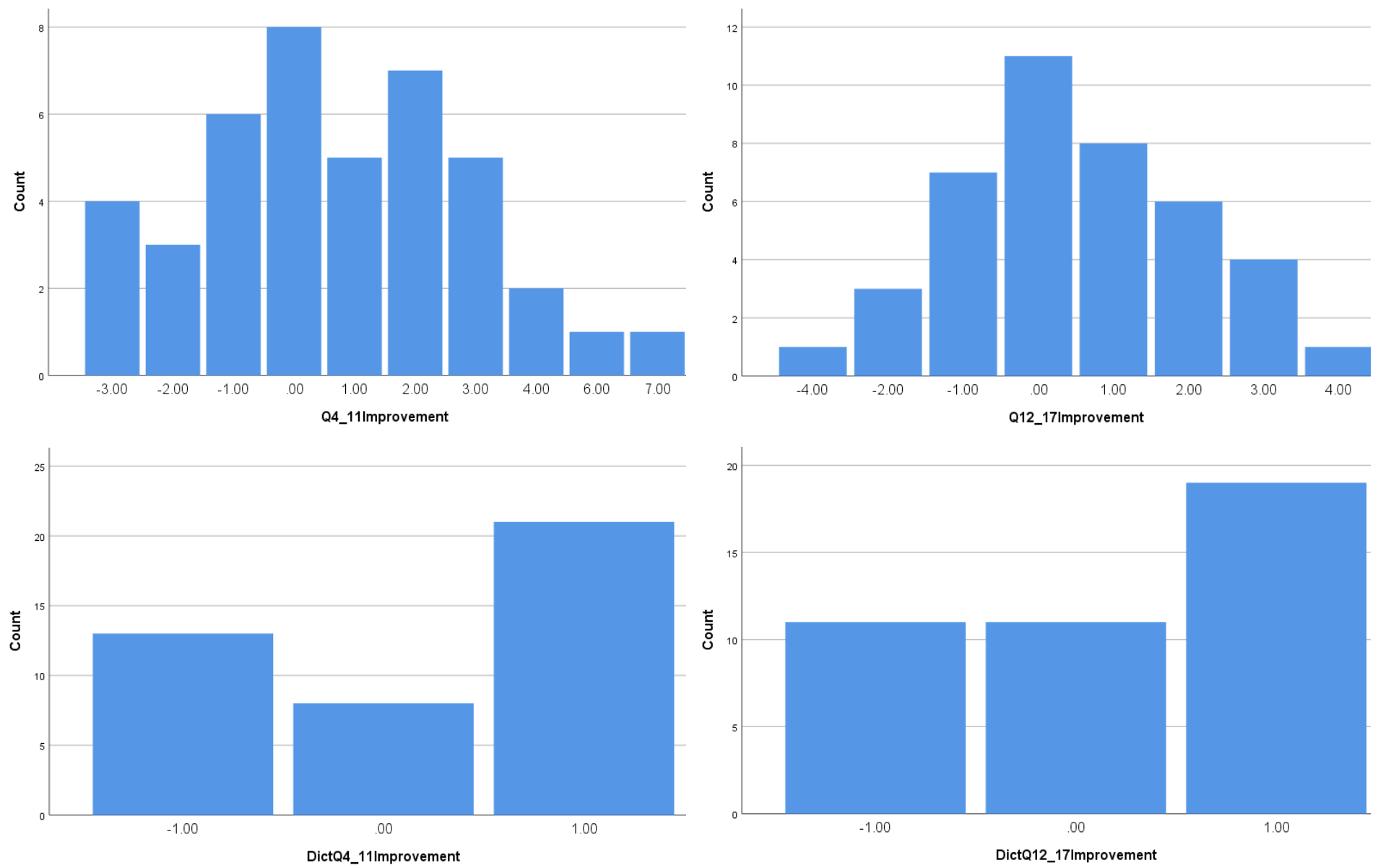

Figure 2. Q 4-11 and Q 12-17 pre and post changes.

\section{DISCUSSION}

Students had misconceptions about antibiotics in the pre-survey: antibiotics treat viruses and all germs and were comparable to the findings of Broniatowski et al. (2015). Antibiotic Knowledge (Q1-3) showed there was a significant improvement of $10 \%$ immediately post-appointment. Students were able to more appropriately identify that antibiotics treated bacteria and not viruses in the post-survey period. Students enrolled in the Arts and Sciences or College of Business programs scored more poorly on Antibiotic Knowledge (Q1-3) than students enrolled in health science undergraduate and graduate programs. These students may be a better focus for future interventions. Appropriate Management of Prescriptions (Q18-19) revealed no significant improvement, as all but two students answered both questions correctly in the pre-survey period.

Students responded in the pre-survey it was better to take an antibiotic than to take the risk of not improving, a finding similar to Broniatowski et al. (2015). The post-survey yielded changes in these responses. Antibiotic Efficacy/Risk versus Benefit (Q 4-11) and Provider Trust (Q12-17) showed that most participants did benefit from the intervention and their answers moved in the more correct direction. However, one-third students responded with the same answers in the pre and post-period.

Ninety-eight percent of students were satisfied with the visit regardless of whether or not an antibiotic was prescribed. Eight students responded that they did not know why or why not an antibiotic was given but still responded that they were satisfied. This could imply that while the knowledge did not increase in these students, the 
time the provider spent trying to educate the patient was appreciated (Belongia, Naimi, Gale, \& Besser, 2002; Coenen et al., 2013).

Limitations include the Nebraska law age restrictions, small sample size, and short time frame for data collection. The small sample size limits the ability of the data to be generalized to the college-age population. Data was collected from September 1, 2017 - December 11, 2017 and viruses may not have been as prevalent during this time frame. Furthermore, surveying participants immediately after the visit may not be a rigorous enough reflection of actual knowledge increase. Post-intervention results could have been influenced if participants recognized questions or responses from the initial survey.

\section{CONCLUSION}

The results of this project show there is a need for future research of this age group's knowledge of antibiotics and the efficacy of educational interventions aimed at the specific population. Due to the limitations of a small sample size at one student health location, it may not be representative of the college student population. Future projects should focus on larger sample sizes at larger, more diverse universities. Future studies should more rigorously analyze students by surveying them at a later date post-intervention to determine if knowledge was truly improved. Overall, the results signify the need for patient education of antibiotic use, specifically in the age group of 19 - 25 years.

The outcomes of this project show that the 19 - 25 age group benefit from educational handouts and verbal education from the healthcare provider about antibiotics and URIs. Knowledge of antibiotic use improved and patients understood why they were not needed. Out of 44 students, only 11 received antibiotics, and those who did not receive antibiotics all understood why. However, due to a limited sample size, the results of this project cannot be generalized to the general population. College health centers can act as leaders in promoting education and antibiotic stewardship.

The ultimate goal of this quality improvement project will be to develop a sustainable educational tool for providers to continue to use after the project's completion. Sustainability may be achieved by incorporating the educational handout into the EMR and automatically printing it in the form of an after-visit summary provided to the patient. Additional considerations for sustainability may be identified as the project is implemented. 


\section{REFERENCES}

Ashworth, M., White, P., Jongsma, H., Schofield, P., \& Armstrong, D. (2016). Antibiotic prescribing and patient satisfaction in primary care in England: cross-sectional analysis of national patient survey data and prescribing data. British Journal of General Practice, 66(642), e40-e46 7p. https://doi.org/10.3399/bjgp15X688105

Barlam, T.F., Soria-Saucedo, R., Cabral, H.J., Kazis, L.E. (2016). Unnecessary antibiotics for acute respiratory tract infections: Association with care setting and patient demographics. https://doi.org/10.1093/ofid/ofw045

Belongia, E.A., Naimi, T.S., Gale, C.M., \& Besser, R.E. (2002). Antibiotic use and upper respiratory infections: A survey of knowledge, attitudes, and experience in Wisconsin and Minnesota. Preventive Medicine, 34(3), 346352. https://doi.org/10.1006/pmed.2001.0992

Broniatowski, D. A., Klein, E. Y., \& Reyna, V. F. (2015). Germs are germs, and why not take a risk? Patients' expectations for prescribing antibiotics in an inner-city emergency department. Medical Decision Making, 35(1), 60-67. https://doi.org/10.1177/0272989X14553472

Cals, J. W. L., Boumans, D., Lardinois, R. J. M., Gonzales, R., Hopstaken, R. M., Butler, C. C., \& Dinant, G. (2007). Public beliefs on antibiotics and respiratory tract infections: An internet-based questionnaire study. British Journal of General Practice, 57(545), 942-947. https://doi.org/10.3399/096016407782605027

Centers for Disease Control and Prevention. (2013). Antibiotic resistance threats in the United States, 2013. Retrieved from http://www.cdc.gov/drugresistance/federal-engagement-in-ar/national-strategy/index.html

Coenen, S., Francis, N., Kelly, M., Hood, K., Nuttall, J., Little, P., .. Butler, C.C. (2013). Are patient views about antibiotics related to clinician perceptions, management, and outcome? A multi-country study in outpatients with acute cough. PLOS ONE 8(10), 1-9. https://doi.org/10.1371/journal.pone.0076691

Crocker, A., Alweis, R., Scheirer, J., Schamel, S., Wasser, T., \& Levingood, K. (2013). Factors affecting adherence to evidence-based guidelines in the treatment of URI, sinusitis, and pharyngitis. Journal of Community Hospital Internal Medicine Perspectives, 3(2), 1-4. https://doi.org/10.3402/jchimp.v3i2.20744

Dempsey, P.P., Businger, A.C., Whaley, L.E., Gagne, J.J., \& Linder, J.A. (2014). Primary care clinicians' perceptions about antibiotic prescribing for acute bronchitis: A qualitative study. Biomedical Family Practice, 15(194), 1-10. https://doi.org/10.1186/s12875-014-0194-5

Fairlie, T., Shapiro, D.J., Hersh, A.L., Hicks, L.A. (2012). National trends in visit rates and antibiotic prescribing for adults with acute sinusitis. Archives of Internal Medicine, 172(19), 1513-1514.

https://doi.org/10.1001/archinternmed.2012.4089

Fletcher-Lartey, S., Yee, M., Gaarslev, C., \& Kahn, R. (2016). Why do general practitioners prescribe antibiotics for upper respiratory tract infections to meet patient expectations: A mixed methods study. BMJ Open, 6, 1-8. https:/ / doi.org/10.1136/bmjopen-2016-012244

Gaarslev, C., Yee, M., Chan, G., Fletcher-Lartey, S., \& Kahn, R. (2016). A mixed methods study to understand patient expectations for antibiotics for an upper respiratory tract infection. Antimicrobial resistance and infection control, 5(39). https://doi.org/10.1186/s13756-016-0134-3 
Haltiwanger, K. A., Hayden, G. F., Weber, T., Evans, B. A., \& Possner, A. B. (2001). Antibiotic-seeking behavior in college students: What do they really expect? Journal of American College Health, 50(1), 9-13.

https://doi.org/10.1080/07448480109595705

Katz, D.L., Elmore, J.G., Wild, D.M.G., \& Lucan, S.C. (2014). Jekel's epidemiology, biostatistics, preventive Medicine, and public health. Philadelphia, PA: Saunders.

Macfarlane, J., Holmes, W., Gard, P., Thornhill, D., Macfarlane, R., \& Hubbard, R. (2002). Reducing antibiotic use for acute bronchitis in primary care: Blinded, randomised controlled trial of patient information leaflet. BMJ: British Medical Journal (International Edition), 324(7329), 91-94. https://www.bmj.com/content/324/7329/91.1

Moerenhout, T., Borgermans, L., Schol, S., Vansintejan, J., Van De Vijver, E., \& Devroey, D. (2013). Patient health information materials in waiting rooms of family physicians: Do patients care? Patient Preference and Adherence, 7, 489-497. https://doi.org/10.2147/PPA.S45777

Nichol, K. L., D'Heilly, S., \& Ehlinger, E. P. (2005). Colds and influenza-like illness in university students: Impact on health, academic and work performance, and health care use. Clinical Infectious Diseases, 40, 1263-1270. https://doi.org/10.1086/429237

Nicoteri, J. A., \& Arnold, E. C. (2005). The development of health care-seeking behaviors in traditional-age undergraduate college students. Journal of the American Academy of Nurse Practitioners, 17(10), 411-415. https://doi.org/10.1111/j.1745-7599.2005.00071.x

Smith, S.S., Kern, R.C., Chandra, R.K., Tan, B.K., \& Evans, C.T. (2013). Variations in antibiotic prescribing of acute rhinosinusitis in United States ambulatory settings. Otolaryngology-Head \& Neck Surgery, 148(5), 852-859. https://doi.org/10.1177/0194599813479768

Smith, T. J., Rigassio-Radler, D., Denmark, R., Haley, T., \& Touger-Decker, R. (2012). Effect of Lactobacillus rhamnosus LGG ${ }^{\circledR}$ and Bifidobacterium animalis ssp. lactis BB-12® on health-related quality of life in college students affected by upper respiratory infections. British Journal of Nutrition, 109(11), 1999-2007. https://doi.org/10.1017/S0007114512004138

Turner, J. C., \& Keller, A. (2015). College health surveillance network: Epidemiology and health care utilization of college students at US 4-year universities. Journal of American College Health, 63(8), 530-538. https://doi.org/10.1080/07448481.2015.1055567

Unwin, B.K., Goodie, J., Reamy, B.V., \& Quinlan, J. (2013). Care of the College Student, American Family Physician, $88,596-604$.

Wutzke, S. E., Artist, M. A., Kehoe, L. A., Fletcher, M., Mackson, J. M., \& Weekes, L. M. (2006). Evaluation of a national programme to reduce inappropriate use of antibiotics for upper respiratory tract infections: Effects on consumer awareness, beliefs, attitudes and behaviour in Australia. Health Promotion International, 22(1), 5364. https://doi.org/10.1093/heapro/dal034 
Address author correspondence to:

Catherine Carrico

Creighton University College of Nursing

2500 California Plaza

Omaha, NE 68178

cathycarrico@creighton.edu

Katie Moes

katiemoes@creighton.edu

\section{Acknowledgements}

Nathan Haecker, MD 


\section{APPENDIX-I}

\section{SURVEY QUESTIONS}

Below are 19 statements regarding antibiotic use. Please rate how strongly you agree or disagree with each statement by circling one of the following for each statement:

\section{Strongly disagree}

\section{Disagree}

Neither agree nor disagree

Agree

Strongly agree

Please complete this survey within 1 week of your student health visit. When you have completed the survey, please place it in the pre-addressed, stamped envelope and mail it. DO NOT write your name, address, or any identifying information on this survey or the envelope. By mailing this survey, your participation in this project is complete. Thank you for your participation!

1 Antibiotics work against bacteria

Strongly disagree Disagree Neither agree nor disagree Agree Strongly agree

2 Antibiotics work against viruses

Strongly disagree Disagree Neither agree nor disagree Agree Strongly agree

3 Antibiotics work against all germs

Strongly disagree Disagree Neither agree nor disagree Agree Strongly agree

4 Antibiotics might not make me better, but it is better to be safe than sorry, so I should take them

Strongly disagree Disagree Neither agree nor disagree Agree Strongly agree

5 Antibiotics might not make me better, but I should take them just in case

Strongly disagree Disagree Neither agree nor disagree Agree Strongly agree

6 I don't know if an antibiotic can make me better, but it can't hurt to take them

Strongly disagree Disagree Neither agree nor disagree Agree Strongly agree

7 Antibiotics have side effects, so I should take them only when I know they will work

Strongly disagree Disagree Neither agree nor disagree Agree Strongly agree

8 My symptoms will only go away with antibiotics

Strongly disagree Disagree Neither agree nor disagree Agree Strongly agree 
9 I will get better even if I don't take antibiotics

Strongly disagree Disagree Neither agree nor disagree Agree Strongly agree

10 If I take antibiotics, I will get better

Strongly disagree Disagree Neither agree nor disagree Agree Strongly agree

11 Antibiotics always cure my symptoms

Strongly disagree Disagree Neither agree nor disagree Agree Strongly agree

12 If a medical provider takes my illness seriously, he or she will give me an antibiotic

Strongly disagree Disagree Neither agree nor disagree Agree Strongly agree

13 A medical provider will not always give me an antibiotic, even if he or she believes I am really sick Strongly disagree Disagree Neither agree nor disagree Agree Strongly agree

14 A good medical provider knows best when antibiotics are needed

Strongly disagree Disagree Neither agree nor disagree Agree Strongly agree

15 I trust the medical provider will give me an antibiotic if I am sick

Strongly disagree Disagree Neither agree nor disagree Agree Strongly agree

16 It is worth it to go to the medical provider because I will get an antibiotic

Strongly disagree Disagree Neither agree nor disagree Agree Strongly agree

17 I feel bad enough to have come to the medical provider so I should get an antibiotic

Strongly disagree Disagree Neither agree nor disagree Agree Strongly agree

18 I can stop taking my antibiotic early if I begin to feel better

Strongly disagree Disagree Neither agree nor disagree Agree Strongly agree

19 I can share my antibiotic with my friend or family member who is also sick

Strongly disagree Disagree Neither agree nor disagree Agree Strongly agree 